\title{
La dimensión simbólica, sustantiva y operativa en las políticas autonómicas de servicios sociales en España $(1982-2008)^{2}$
}

\author{
José Adelantado \\ Instituto de Gobierno y Políticas Públicas (IGOP), \\ Universitat Autònoma de Barcelona \\ <jose.adelantado@uab.cat>
}

\section{Mariña Couceiro}

Instituto de Gobierno y Políticas Públicas (IGOP), Universitat Autònoma de Barcelona

\section{Mariela Iglesias}

Instituto de Gobierno y Políticas Públicas (IGOP), Universitat Autònoma de Barcelona

\section{Julio Souto}

Instituto de Gobierno y Políticas Públicas (IGOP), Universitat Autònoma de Barcelona

Artikulu honetan aztergai hartzen dira Espainiako 1982 eta 2008 urteen arteko gizarte-zerbitzuetako erkidegoen politikak berauen dimentsio sinbolikoan (zein norabide berri hartu dute balio eta objektuek?), oinarrizkoan (zein premia eta zein intentsitatean betetzen dira?) eta operatiboan (nola hornitu, antolatu eta kudeatzen dira zerbitzuak?). Politika horren definizio normatiboan ematen den diskurtsoen homogeneotasunak oinarri hartzen ditu difusio-prozesuak, eta oinarrizko dimentsioan zerbitzuak eskaintzean emandako sektore pribatuaren zabaltze-joeran (irabazi asmoz eta irabazteko asmo gabe), eta tartean sartu diren onuradunen plan indibidualizatuen ordain gisako definizioan eta finantzaketan (koordainketa). Aldiz, desberdintasunek oinarrizko aukerei eragiten diete gehiagoan, izan ere, derrigorrezko gutxiengo komun bat ez egoteak eragiten baitie erkidego autonomoei, eta horren ondorioz, gastu-mailak eta intentsitatetasa edota estaldurak ez dute erantzunik ematen premia-irizpide objektiboei.

\section{HITZ-GAKOAK:}

Erkidegoetako politikak, gizarte-zerbitzuak, dimentsio sinbolikoa, oinarrizko dimentsioa, dimentsio operatiboa.
Este artículo analiza la evolución de las políticas autonómicas de servicios sociales en España entre 1982 y 2008 en su dimensiones simbólica (¿en qué dirección han cambiado los valores y objetivos?), sustantiva (¿qué necesidades se cubren y con qué intensidad?) y operativa (¿cómo se proveen, organizan y gestionan los servicios?). La elevada homogeneidad discursiva existente en la definición normativa de esta política se sustenta a través de procesos de difusión y, en la dimensión sustantiva, por la tendencia expansiva del sector privado (con y sin ánimo de lucro) en la prestación de servicios, y por la involucración de los beneficiarios en la definición de su plan individual de contrapartidas y en la financiación (copago). En cambio, las disparidades afectan más a las opciones sustantivas, pues, debido a la inexistencia de un mínimo común obligatorio para todas las comunidades autónomas, ni el nivel de gasto ni las tasas de intensidad o cobertura parecen responder a criterios objetivos de necesidades.

\section{Palabras clave:}

Políticas autonómicas, servicios sociales, dimensión simbólica, dimensión sustantiva, dimensión operativa.

${ }^{1}$ Este artículo es un resumen de tres capítulos escritos por los autores y editados originalmente en catalán en el libro dirigido por Raquel Gallego y Joan Subirats Autonomies i desigualtats a Espanya: percepcions, evolució social i polítiques de benestar (Institut d’Estudis Autonòmics, 2011). 


\section{Introducción}

El objetivo de este escrito es estudiar la evolución de las políticas autonómicas de servicios sociales en España entre 1982 y 2008 . El trabajo se centra en tres ejes clásicos del análisis de políticas: las dimensiones simbólica, sustantiva y operativa.

La dimensión simbólica hace referencia a los aspectos que nos sirven para conceptualizar el modelo o sistema de servicios sociales. Hablamos, por lo tanto, del análisis de principios, ideas y valores que se proclaman como definitorios e identificativos del sistema. Prestaremos atención a tres aspectos fundamentales:

- El peso de la trayectoria histórica en la evolución de la política y su relación con el proceso de europeización y el poder de cambio que pueden tener las ideas: ¿ha habido un cambio de paradigma?

- La importancia de las ideas y los discursos en las leyes autonómicas de servicios sociales, esto es, el marco ideológico y conceptual que define al sistema: ¿estos discursos normativos se corresponden con la realidad concreta de los sistemas de servicios sociales?

- La influencia de las ideas y los discursos de la UE sobre pobreza, inserción e inclusión en esta política: ¿a qué tipo de personas se le reconocen los derechos, a toda la población, a colectivos en situación de necesidad?

La dimensión sustantiva trata del contenido de las políticas (necesidades que cubren, intensidad y extensión), y nos tendría que permitir ver y analizar el grado de reconocimiento o visibilidad política que tienen los servicios sociales. Nos centraremos en tres aspectos:

- El proceso de descentralización en la Constitución y en las leyes autonómicas de servicios sociales: ¿en todas las comunidades autónomas se ha llegado al mismo grado de descentralización en relación a la administración local?

- La financiación mediante el análisis del nivel de gasto y de la prioridad dada a los servicios sociales dentro de los presupuestos autonómicos: ¿ha habido un aumento del gasto y de los recursos destinados al sector de servicios sociales por parte de los diferentes Gobiernos autonómicos?

- El nivel de cobertura extensiva e intensiva del sistema: ¿podemos hablar de atención universal?, ¿qué necesidades se cubren, a qué colectivos se atiende?

En el apartado de la dimensión operativa, nos centramos en el análisis del 'cómo'; estudiamos los instrumentos empleados en la intervención, es decir, los aspectos de gestión (formas de provisión, organización y gestión de los servicios) y las pautas de interacción entre los diferentes actores que intervienen. Aquí, tendremos en cuenta los siguientes aspectos:
- Red de actores y participación ciudadana. Estudiaremos el grado de complejidad de la red de actores, intentaremos analizar el peso y la presencia de actores públicos y privados en la red: ¿hay especialización funcional en la prestación de servicios entre actores públicos, mercantiles y tercer sector?

- Recursos humanos: miraremos el peso relativo del sector, la expansión que ha tenido y las características de los profesionales

- Formas de gestión. Se analizará la planificación, la división organizativa y los modelos de provisión de servicios: ¿hay diferencias en la tipología de intervención, prestación de servicios, regulación, transferencias directas o indirectas?

Así, el artículo se estructura en el análisis de las tres dimensiones mencionadas y, finalmente, extrae unas conclusiones generales.

\section{Dimensión simbólica²}

En este apartado se estudian los cambios y continuidades en las políticas autonómicas de servicios sociales, y se abordan las conexiones entre los cambios de paradigma en las políticas, su europeización y el poder de las ideas y los discursos públicos.

El análisis se inscribe en los debates académicos sobre los paradigmas de políticas (Hall, 1993), que a su vez reactivaron el debate teórico en torno a las limitaciones explicativas del teorema de los patrones de dependencia (Mahoney, 2000; Ebbinghaus, 2005). En cuanto a la europeización, el estudio parte de la perspectiva de Radaelli (2003), que identifica cuatro reacciones diferentes de los Estados frente a los cambios inducidos por la Unión Europea. Asimismo, se entiende la europeización como un proceso de gobernanza multinivel que afecta a la recomposición vertical y horizontal del poder doméstico (Börzel, 2002). El estudio empírico se realiza a través de la selección de algunos marcos interpretativos (framing) presentes en las leyes de servicios sociales, rentas mínimas de inserción y planes autonómicos de inclusión social. El marco teórico de referencia es el institucionalismo discursivo (Schmidt, 2008), que pretende captar el poder explicativo de las ideas y los discursos.

\subsection{Patrones de dependencia, europeización y poder causal de las ideas en los cambios de paradigma}

En la literatura sobre institucionalismo, se distinguen como mínimo dos interpretaciones del path dependence. Una, cercana a la idea de reproducción, se

\footnotetext{
${ }^{2}$ Adelantado, J. (2011): "La dimensió simbòlica en les polítiques autonòmiques de serveis socials i assistència social”, en Gallego, R.; y Subirats, J. (dirs.), Autonomies $i$ desigualtats a Espanya: percepcions, evolució social i polítiques de benestar, Barcelona, Institut d’Estudis Autonòmics, págs. 319-340.
} 
asocia a un mecanismo de retroalimentación interna donde el cambio sólo puede surgir de factores exógenos. Desde otra perspectiva más dinámica, el cambio se entiende como una cadena de acontecimientos temporales ordenados y causalmente conectados, que no tienden a reproducir los patrones, sino a transformarlos a través de un proceso de reacciones y contra reacciones. Según Ebbinghaus (2005), el path dependence restringe la elección, pero no determina el paso siguiente y la transformación puede suceder por:

- Path stabilization: adaptación marginal al entorno sin cambio en los principios.

- Path departure: adaptación gradual con renovación parcial de las instituciones y redirección de los principios.

- Path cessation o path switching: acontecimiento que acaba con el autorrefuerzo en una institución establecida que puede dar paso a otra nueva en su lugar.

Entre las explicaciones del cambio institucional, la teorización más reconocida es la de Hall (1993). Según este autor, un paradigma de política es una carcasa interpretativa de ideas y patrones que especifica no solamente los objetivos de política y el tipo de instrumentos que pueden usarse para conseguirlos, sino también la naturaleza de los problemas y la forma de pensarlos y comunicarlos (discursos). Hall estudia cómo se pasa de un paradigma de política a otro a partir de tres órdenes de cambio: a) ajuste de los instrumentos disponibles; b) cambio de instrumentos o técnicas, pero sin modificar la jerarquía de objetivos; c) cambio radical y simultáneo de instrumentos y objetivos.

Las críticas al teorema del path dependence señalan, por un lado, sus limitaciones explicativas para procesos que implican factores de cambio exógenos, como son los procesos de globalización o europeización; $y$, por otro, que se centran en una visión estática que se confiere a las ideas. Junto a los 'viejos' institucionalismos, las teorías del path dependence no han considerado las ideas como factor de cambio efectivo (Schmidt, 2008). Frente a esto, el institucionalismo discursivo que propone Schmidt entiende que el cambio institucional puede surgir después de un cambio cognitivo o normativo en los valores o las creencias subjetivas de los actores, que son cambiantes según sus intereses. La transformación institucional se explica, entonces, por la inconsistencia de los marcos cognitivos dominantes en la sociedad y la deslegitimación de la institución. Por ello, la emergencia de nuevas ideas puede poner en duda el esquema cognitivo y llevar a un cambio de paradigma.

En cuanto a la europeización, se entiende como un proceso que afecta a la recomposición vertical y horizontal del poder doméstico que opera a través de mecanismos hacia arriba (bottom-up), como la creación y consolidación de entidades supranacionales, y hacia abajo (top-down), mediante la incorporación de reglas y normas europeas en las esferas domés- ticas (Börzel, 2002). Por otra parte, la perspectiva de Radaelli (2003) incluye en su conceptualización procesos de construcción, difusión e institucionalización de reglas formales e informales, procedimientos, paradigmas de política, estilos o formas de hacer las cosas, valores y normas compartidas que inicialmente se definen y consolidan en el proceso político de la UE, y que, posteriormente, son incorporados en el discurso de las políticas públicas internas. El autor identifica cuatro reacciones frente a los cambios inducidos por la UE: a) inercia como ausencia de cambio, porque la adaptación a los requerimientos resulta demasiado costosa; b) absorción, que indica la incorporación de cambios que no modifican el núcleo y entramado esencial de la política; c) transformación, similar al tercer orden de Hall, que implica un cambio de paradigma; y d) reducción de la europeización.

Otra cuestión es el cambio que implica la fragmentación del Estado en múltiples unidades subnacionales y su integración en organizaciones intergubernamentales: procesos que provocan repartos verticales de poder entre múltiples niveles de gobierno; y horizontales, entre múltiples actores (Hooghe y Marks, 2001). El Estado es desafiado desde arriba, por la integración y la globalización; desde abajo, por movimientos subnacionales, como los nuevos regionalismos; y desde los costados, por el papel de la sociedad civil en el siglo XXI (Loughlin, 2007).

\subsection{Ideas y discursos en las leyes autonómicas de servicios sociales}

A continuación se presenta el análisis longitudinal de tres marcos interpretativos en las leyes autonómicas de servicios sociales desde la transición democrática hasta 2008.

\subsubsection{Marco interpretativo 1: universalismo y responsabilidad pública (1982-1992)}

Entre 1982 y 1992 , se promulgan las primeras leyes de servicios sociales en todas las comunidades autónomas amparadas en la competencia "exclusiva" que permite el art. 148.1.20 de la Constitución española. La voluntad estatalizadora de los servicios sociales constituye un eje común desplegado bajo las ideas de universalismo y responsabilidad pública. El universalismo supuso una respuesta teórica e ideológica a la beneficencia y al asistencialismo que caracterizaron la época franquista (Roldán y García Giráldez, 2006) y fue un propósito de reconocimiento de la igualdad de derecho al bienestar social de todos los ciudadanos. El principio de responsabilidad pública como compromiso institucional, técnico y financiero de las administraciones en cuanto a las prestaciones de servicios sociales se concebía también como la solución a un sistema benéfico y residual donde primaban las organizaciones altruistas de asistencia tradicional (Cáritas, Cruz Roja, ONCE). En cuanto al reconocimiento del derecho a los servicios 
sociales, en la Constitución no aparece explícitamente. Tampoco la Ley de Bases del Régimen Local (7/1985) aclara responsabilidades, ni concreta servicios, aunque establece que la prestación de servicios sociales y reinserción social será competencia obligatoria en municipios de más de $\mathbf{2 0 . 0 0 0}$ habitantes. Las primeras leyes de servicios sociales anuncian aspiraciones generales sin garantía del derecho, ni mecanismos de reclamación para hacerlo efectivo, y sin previsión o compromiso de recursos económicos y humanos. Asimismo la descentralización desplegada por los estatutos de autonomía, ha afectado a la organización institucional que conforma un mosaico de diecisiete sistemas con desigualdades territoriales entre y dentro de las autonomías.

\subsubsection{Marco interpretativo 2: privatización y altruismo (1993-2003)}

En 1993 se inicia, por parte de Galicia, un proceso de reforma a través de cambios incrementales que progresivamente adoptarán las leyes reformadas de servicios sociales en todas las comunidades autónomas. A través de los marcos discursivos de privatización y voluntariado social, se expresa una reorientación hacia la liberalización y privatización de los servicios sociales. Estas leyes reconocen el voluntariado social en torno al tercer sector $y$, especialmente, favorecen la integración en el sistema de la iniciativa privada lucrativa, por medio de la concertación en la prestación de servicios. Algunas comunidades autónomas empiezan a incorporar las transferencias de recursos monetarios a los usuarios (cheque-servicio).

\subsubsection{Marco interpretativo 3: subjetivación de derechos y copago (2003-2008)}

La segunda generación de leyes de servicios sociales se despliega desde 2000 (La Rioja, 2002; Asturias, 2003; Madrid, 2003; Murcia, 2003; Cataluña, 2006; Navarra, 2006; Cantabria, 2007; País Vasco, 2008; Galicia, 2008). Probablemente por influencia de las instancias europeas a partir del Consejo Europeo de Niza (2000), incorporan un discurso en torno al marco de los derechos subjetivos con garantía jurídica de acceso universal, que concretan mediante la definición de las prestaciones en carteras de servicios. En el caso de Cataluña, se individualiza el derecho, con consecuencias en la comprobación individual y no familiar de recursos. Entre las innovaciones, destaca la incorporación de derechos y deberes del usuario: derecho a la información sobre prestaciones y recursos, a la participación en la toma de decisiones, a la libre elección de medidas y recursos aplicables; deber de participar activamente en el proceso de mejora, destinar las prestaciones a la finalidad original, acudir a las entrevistas con profesionales y seguir las indicaciones que realicen (Alemán y García Serrano, 2005). También se refuerza la idea de cofinanciación a partir del copago, para lo que se tiene en cuenta el patrimonio e ingresos del usuario. Incluso, algunas comunidades autónomas introducen instrumentos que favorecen las transferencias monetarias en lugar de la prestación de servicios (Valencia desde 1997 y Madrid desde 2003).

\subsection{Ideas y discursos de la UE sobre la pobreza, la inserción y la inclusión. La reacción de España}

En este apartado se consideran tres marcos interpretativos que ilustran la emergencia, consolidación y revisión del paradigma liberal.

\subsubsection{Marco interpretativo 4: pobreza y derecho a la inserción (1975-1996)}

El correlato del discurso europeo sobre la pobreza lo constituye en España el Programa para Situaciones de Necesidad (1987). En 1989, se incorporan acciones de Pobreza III, que implican el acceso a una protección mínima para una parte significativa de la población (Ley de prestaciones no contributivas de la Seguridad Social, 26/1990). En este periodo, las comunidades autónomas implementan los programas regionales de rentas mínimas de inserción (RMI) impulsados por diferentes factores: acción combinada de políticos y técnicos; presión de los partidos de oposición; movilización de las secciones regionales de los principales sindicatos y, en algunas comunidades autónomas, el soporte de ONG como Cáritas (Arriba, 2002). Las RMI, sin embargo, tienen un papel residual y subsidiario respecto a otros esquemas de protección de la Seguridad Social. Su implantación en las diferentes comunidades autónomas comparte aspectos normativos y de concesión, pero presenta un mosaico complejo de denominaciones, contenidos, estrategias y resultados. En su evolución, estas diferencias se profundizan, a excepción de la introducción de criterios de activación en los sistemas de asistencia social con restricciones al acceso y en la vinculación con las políticas de empleo (Laparra, 2004). De este modo, la última red de protección tiende a convertirse en un trampolín hacia el empleo. Según Aust y Arriba (2006), la cuestión central en los debates académicos y en la agenda política deja de ser la pobreza y pasa a ser la inclusión social.

\subsubsection{Marco interpretativo 5: crecimiento, empleo y cohesión social (1997-2005)}

La firma del Tratado de Ámsterdam (1997) y la Cumbre de Luxemburgo introdujeron los primeros cambios en la política social europea, pero fue a partir de la Cumbre de Lisboa (2000) cuando se dio un giro importante hacia el reconocimiento y fomento de la cohesión social en Europa. La estrategia de Lisboa se basaba en la relación entre el desarrollo económico, el empleo y la cohesión social, y se proponía erradicar la pobreza en 2010. También a partir de Lisboa y Niza se aprueba el Método Abierto de Coordinación. Se trata de un instrumento de coordinación a escala europea de la política social desarrollada a escala nacional. De esta forma, la Comisión cumplirá una función de 
estímulo, pero la responsabilidad de la lucha contra la pobreza y exclusión será de los Estados miembros. En España, desde 2001 se siguió este marco a través de la elaboración de cinco planes nacionales de acción para la inclusión social (PNAIn). Cada uno de ellos, supone un avance en el sentido señalado por las recomendaciones europeas. El PNAIn-II (2003-2005) fomentó el despliegue de los planes autonómicos de inclusión social (PAIn), incentivó la participación de las personas afectadas y la atención integral y coordinada de grupos y personas vulnerables, con un enfoque transversal y de género. Después de los dos primeros planes, la Comisión insiste, a través de informes, en las políticas activas hacia el empleo, en las políticas sectoriales (educación, salud, vivienda), y en colectivos como infancia, inmigrantes y minorías étnicas. Por otra parte, los PNAIn reconocen el actual sistema de descentralización con amplias competencias de las comunidades autónomas y un rol de gestión hacia los ayuntamientos.

\subsubsection{Marco interpretativo 6: crecimiento, empleo y gobernanza (2005-2008)}

En 2005, se replantea la estrategia de Lisboa (Informe Barroso) con dos prioridades: el crecimiento económico y la creación de empleo, entendiendo la inclusión social y la cohesión como las consecuencias derivadas. La nueva agenda social europea (2005-2010), cuyos ejes son el empleo, el crecimiento y, de manera complementaria, la gobernanza, también establece nuevos indicadores y objetivos. Desde finales de la década de 1990 a principios de la de 2000 , catorce de las diecisiete comunidades autónomas habían aprobado, como mínimo, un plan de inclusión. Las que tomaron la iniciativa fueron La Rioja, Castilla-La Mancha, Navarra y Canarias. El siguiente grupo (20012004) coincide con los primeros PNAIn, bajo el marco de la Estrategia Europea de Inclusión Social (Andalucía, Aragón, Castilla y León, Cataluña, Galicia, País Vasco, Madrid y Valencia). La última ola de planes se aprobó posteriormente al replanteamiento de la estrategia de Lisboa (Asturias y Extremadura). Existen otras comunidades autónomas, como Baleares, Cantabria o Murcia, donde no se ha ejecutado ningún plan. Por otra parte, en estos planes se constata la heterogeneidad de aspectos temáticos y de actores implicados (Renes, Lorenzo y Chahin, 2007).

\subsection{Discusión}

Al comparar las ideas, los objetivos e instrumentos de las primeras leyes autonómicas de servicios sociales con las contemporáneas, se puede hablar de un cambio de paradigma. Así, en la política de servicios sociales se pueden distinguir tres ciclos de desarrollo, que muestran la transición desde las aspiraciones a un modelo de Estado de bienestar keynesiano a otro de tipo schumpeteriano alrededor del workfare state. El primer, ciclo que va desde la transición democrática hasta mediados de años noventa, se expresa en las primeras leyes de servicios sociales (1982-92), que tenían como objetivo la universalización y responsabilidad pública y, aunque no culminaron su desarrollo, significaron una importante institucionalización de esta política (si bien continuaron operando en clave asistencialista, teniendo en cuenta la inexistencia de un derecho subjetivo). Los instrumentos para conseguirlos eran fundamentalmente públicos, a través de una red institucional formada por consejerías, concejalías y centros de servicios sociales; y el discurso estaba fuertemente influido por el esquema cognitivo de técnicos y trabajadoras de servicios sociales. Las consecuencias de la crisis económica de finales de los setenta, especialmente el desempleo, y el acceso de España en la Comunidad Europea en 1986 facilitaron que otra de las consecuencias, la pobreza, entrara al escenario cognitivo. Entre 1989 y 1995 , se aprobaron leyes de RMI en todas las comunidades autónomas; los objetivos de universalidad y responsabilidad pública que declaraban las leyes de servicios sociales se mantuvieron, igual que los instrumentos, puesto que se canalizaron a través de la red institucional y mantuvieron su carácter asistencial. Pero se modificaron los actores: las recomendaciones de las instituciones europeas, los sindicatos, Cáritas, y los partidos opositores en los parlamentos autonómicos fueron los principales impulsores.

El segundo ciclo de la política de servicios sociales es de transición de un paradigma al otro, y se extiende desde mediados de la década de 1990 a principios de la del 2000. En este periodo, se produjo una adaptación gradual, con renovación parcial de las instituciones y redirección de los principios (path departure), y también un cambio de instrumentos (segundo orden de cambio) y una reacción adaptativa a los cambios inducidos por la UE en forma de ‘absorción'. En las reformas de las leyes autonómicas de servicios sociales, se observa un tránsito desde los objetivos de universalismo y responsabilidad pública hacia los de privatización y altruismo. Los instrumentos dejan de ser exclusivamente públicos, puesto que se reconoce la presencia de la iniciativa privada lucrativa y se delegan funciones de prestación de servicios al tercer sector. La emergencia de nuevos actores se explica por la potencia sustantiva y comunicativa para promover un cambio de marco cognitivo que se puede resumir en menos Estado, más mercado y más sociedad civil (voluntariado). Las críticas a los monopolios de los servicios públicos del 'Estado del bienestar' dieron paso a la 'sociedad del bienestar', con nuevos imaginarios sobre lo que tienen que ser y cómo han de actuar las administraciones públicas. Las políticas asistenciales, como las RMI (adscritas a la Estrategia Europea de Inclusión Social), se vinculan con las políticas laborales de empleo y, a su vez, la laxitud en el cumplimiento de objetivos que permite el Método Abierto de Coordinación ha hecho posible la producción de planes nacionales para la inclusión social que otorgan una enorme discrecionalidad a los Estados miembros y a las instituciones subnacionales.

En el último ciclo, desde principios de la década de 2000 hasta 2008 , se consolida el cambio de paradigma. Las nuevas leyes de servicios sociales avanzan 
en un doble sentido: subjetivación de derechos con aportación económica de los beneficiarios, y consolidación de la presencia de la iniciativa privada mercantil y social. Las RMI avanzan en la incorporación diferenciada del derecho a la prestación económica y de actuaciones dirigidas a la integración laboral, mientras se profundiza el vínculo con las políticas de empleo, especialmente a escala local. Durante este periodo, han cesado las herencias universalistas y el monopolio público en la prestación de servicios (path cessation), han cambiado los instrumentos y los objetivos, y por lo tanto, los discursos (tercer orden de cambio), y ha cesado la resistencia a los cambios inducidos por la UE ('transformación'). En la política de servicios sociales, tanto el sistema de financiación de los nuevos derechos -que se realiza mediante un copago del beneficiario en función de su renta y patrimonio (y no mediante impuestos generales)como el impulso de los cheques de diferente tipo (en lugar de promover servicios públicos) ejemplifican el cambio de paradigma. En este periodo, la UE revisa la Estrategia de Lisboa, y a pesar de la persistencia de la pobreza y la exclusión, sus orientaciones se dirigen más bien a la fusión de la Estrategia Europea de Empleo con la Estrategia Europea de Inclusión Social, mediante el concepto de 'activación', para hacer que trabajar sea rentable (making work pay). Esto, según Castel (2002), significa un gran cambio para esta política, que iría desde la atención tradicional a los marginados por parte de los servicios sociales, a la gestión del no empleo.

\section{Dimensión sustantiva ${ }^{3}$}

Para abordar la dimensión sustantiva de las políticas autonómicas de servicios sociales, se considerarán tres ámbitos: el proceso de descentralización, la financiación y la cobertura.

\subsection{El proceso de descentralización}

\subsubsection{La descentralización en la Constitución y en los estatutos de autonomía}

En el área de los servicios sociales, la descentralización ha sido defendida como sinónimo de eficacia y proximidad a la población, sin que ello debiese implicar, en principio, desigualdad territorial. Sin embargo, los desequilibrios entre y dentro de las comunidades autónomas aparecieron muy pronto. El análisis interregional pone de manifiesto el sustrato común de las leyes autonómicas de servicios sociales; no obstante, esta aparente homogeneidad normativa se materializa en una puesta en práctica desigual, favorecida por la total descentralización del sistema y el insuficiente desarrollo normativo (Gaitán, 1991). Esta heteroge-

${ }^{3}$ Couceiro, M. (2011): "La dimensió substantiva en les polítiques autonòmiques de serveis socials”, en Gallego, R.; y Subirats, J. (dirs.), Autonomies $i$ desigualtats a Espanya: percepcions, evolució social $i$ polítiques de benestar, Barcelona, Institut d'Estudis Autonòmics, págs. 341-364. neidad se mantiene en el ámbito intrarregional, a causa de la descentralización hacia las corporaciones locales, sin mecanismos para asegurar la financiación, ni corregir el minifundismo municipal mediante la agregación de entidades (Casado, 2002).

La indefinición constitucional respecto a los servicios sociales posibilitó la descentralización del sistema, pero sólo algunas de las comunidades autónomas reconocieron de manera explícita, en sus estatutos de autonomía, la competencia exclusiva en materia de servicios sociales (Andalucía, Canarias, Castilla-La Mancha, Castilla y León, Murcia). Consecuentemente, la mayoría de las comunidades autónomas asumen la citada competencia haciendo una interpretación amplia del art. 148.1.20 (sobre asistencia social) 0 a través del art. 149.3 (en que se establece que las comunidades autónomas pueden asumir competencias exclusivas en materias no atribuidas al Estado). De esta interpretación amplia, se deriva que algunas comunidades autónomas asuman explícitamente competencias en materia de servicios sociales, y otras, con independencia de la asunción genérica, la adquieran en materias concretas, como infancia, minusvalía o tercera edad.

\subsubsection{La descentralización en las leyes autonómicas de servicios sociales}

El análisis detallado de las diecisiete leyes autonómicas de servicios sociales nos permite llegar a una primera consideración: aunque todas proclamen como principio la descentralización, se aprecia en el contenido una fuerte tendencia centralista, ya que las competencias importantes se asignan a los Gobiernos autonómicos, mientras que a los ayuntamientos se derivan las competencias de mera ejecución. Al mismo tiempo, se aprecia una gran ambigüedad en la distribución de las competencias, lo que produce, por un lado, la indeterminación y las duplicidades de las responsabilidades públicas y, por otro, puede permitir un ejercicio discrecional o abusivo de algunas funciones. Algunas de las competencias más destacadas en el ámbito autonómico serían, en general, las relativas a planificación, desarrollo reglamentario y de legislación en la materia, ordenación y coordinación del sistema, establecimiento y gestión de las prestaciones económicas, y asesoramiento a las entidades prestadoras de servicios. Sobre el ámbito municipal, estas normas otorgan a los ayuntamientos competencias básicamente gestoras del nivel primario y otras relacionadas con la planificación y coordinación de servicios. En general, los servicios sociales de nivel primario se concretan en el ámbito local, sobre todo en el espacio municipal. La creación de una red de servicios sociales de base es la política predominante desde los años ochenta. Por otro lado, el segundo nivel, de servicios sociales especializados es de competencia superior. En definitiva, se puede resumir que (Alonso Seco y Gonzalo, 1997):

- Las comunidades autónomas se reservan la potestad legislativa y, en general, la reglamentaria. 
- Las provincias apenas reciben responsabilidades (excepto en País Vasco, Castilla y León, Baleares y Canarias).

- Municipios y entidades intermunicipales reciben principalmente responsabilidades de ejecución de servicios, especialmente los de primer nivel organizativo.

\subsection{Financiación de las políticas autonómicas de servicios sociales}

La escasa información cuantitativa sobre esta política, en compar ación con otros sectores, se debe a la fragmentación y a la inexistencia de criterios mínimos de unificación. Esto hace muy complejo el análisis comparativo; la información disponible de cada comunidad es muy heterogénea, difícil de recoger y sistematizar. Hasta la fecha, sólo contamos con dos estudios en profundidad (Rodríguez Cabrero, 1990; Barea, 1996), que hacen referencia al mismo periodo (1970-1990).

Disponemos de datos del peso presupuestario de los servicios sociales para dos periodos significativos: el principio de la puesta en marcha de las leyes autonómicas de servicios sociales (1984-1988) y el final del periodo (2002-2005). En la Tabla 1, podemos apreciar la heterogeneidad de la prioridad política atribuida a los servicios sociales atendiendo al porcentaje de presupuesto total de cada comunidad destinado al sector. Si bien la distancia se ha reducido entre 1988 y 2006 (en 1988, Extremadura dedicaba el 15,8\% y Cataluña el 3,3\% [12,5 puntos de diferencia]; y en 2006, Navarra destinaba el $13,6 \%$ y Baleares un 6,2 \% [7,4 puntos de distancia]), aún existe una diferencia elevada entre los porcentajes máximos y mínimos.

Entre 1984 y 1988 , doce comunidades autónomas aprueban sus leyes de servicios sociales; sin embargo, en el mismo periodo, se reducen los presupuestos. Suponemos que la crisis económica afectaría a la partida, ya que al no sustentarse en derechos exigibles, es más fácil que se recorte. En 2002, el proceso de transferencia de competencias ya había concluido. Entre 2002 y 2006 , tal vez a causa de la bonanza económica, casi todas las comunidades reducen los presupuestos dedicados a esta política. Así, igual que en contextos de crisis este sector es el primero en ser recortado, también en épocas de expansión presupuestaria es el último en crecer.

\subsection{Cobertura de los servicios sociales}

\subsubsection{Cobertura extensiva}

A diferencia de las prestaciones sanitarias y educativas, y a pesar del universalismo proclamado en las leyes, la oferta pública de servicios sociales es selectiva, y sigue una política de racionamiento basada en criterios socioeconómicos. Esto surge de la persistencia de una financiación claramente insuficiente para cubrir la demanda, no ya potencial sino manifiesta.
Tabla 1. Presupuesto en servicios sociales respecto al presupuesto total de la comunidad autónoma. España, 1984-2006 (\%)

\begin{tabular}{|c|c|c|c|c|}
\hline $\begin{array}{l}\text { Comunidad } \\
\text { autónoma }\end{array}$ & 1984 & 1988 & 2002 & 2006 \\
\hline País Vasco & - & - & 9,06 & 7,22 \\
\hline Canarias & 0,00 & 6,00 & 11,37 & 8,70 \\
\hline Navarra & 3,29 & 5,66 & 12,57 & 13,60 \\
\hline Valencia & 4,11 & 3,64 & 10,41 & 8,08 \\
\hline Andalucía & 4,37 & 4,79 & 10,44 & 9,81 \\
\hline Cataluña & 4,44 & 3,30 & 8,19 & 8,55 \\
\hline Galicia & 6,81 & 6,08 & 9,76 & 8,86 \\
\hline Extremadura & 8,46 & 15,76 & 13,83 & 13,41 \\
\hline La Rioja & 10,37 & 6,69 & 17,66 & 13,12 \\
\hline Asturias & 11,45 & 8,42 & 14,14 & 10,64 \\
\hline Baleares & 12,05 & 8,85 & 12,67 & 6,18 \\
\hline Cantabria & 12,06 & 6,35 & 14,56 & 9,63 \\
\hline $\begin{array}{l}\text { Castilla y } \\
\text { León }\end{array}$ & 14,57 & 11,54 & 13,20 & 11,26 \\
\hline Aragón & 14,72 & 10,11 & 9,79 & 7,87 \\
\hline Murcia & 16,82 & 15,23 & 11,80 & 8,87 \\
\hline $\begin{array}{l}\text { Castilla-La } \\
\text { Mancha }\end{array}$ & 18,36 & 9,98 & 10,72 & 11,30 \\
\hline Madrid & 25,52 & 10,65 & 12,35 & 10,82 \\
\hline Total & 6,47 & 5,71 & 10,78 & 9,57 \\
\hline
\end{tabular}

Fuente: Elaboración propia a partir de Rodríguez Cabrero (1990: 201 y 205) y Ministerio de Economía y Hacienda (liquidación de presupuestos de las comunidades autónomas de los ejercicios 2002 y 2006 [datos consolidados]).

De esta forma, se continúa, de hecho, con la práctica de beneficencia del periodo anterior a la Constitución de 1978 (Casado, 2007a). Pese al porcentaje de acceso tradicionalmente bajo, podemos intuir que esta tasa de cobertura se habrá incrementado, aunque sin alcanzar una extensión significativa. Esto se puede apreciar observando el número de empresas y entidades de carácter privado en el ámbito de los servicios sociales, cuya evolución en el ámbito estatal muestra un incremento de un 85,4 \% entre 1999 y 2004 (Couceiro, 2011: 352).

Esta escasez y selectividad comporta el peligro de la estigmatización, que ya se producía ampliamente por la acción de la beneficencia. Esta estigmatización sería doble: por un lado, la estigmatización de los servicios, que disuade de su utilización a los que podrían acceder a ellos pagando un precio de mercado; y al mismo tiempo, la estigmatización social de los usuarios. Esto comporta que, en general, los servicios sociales sean poco conocidos y utilizados, y que sólo los sectores excluidos hagan un uso repetido y habitual. Sobre este asunto, para Demetrio Casado (2007b) la realización efectiva del principio de universalidad comportaría la utilización de los servicios públicos en función de necesidades técnicas, con independencia de las circunstancias sociales. Sin embargo, el sistema todavía cuenta con importantes barreras de acceso. 
Otro elemento que limitaría la extensión de la cobertura es la falta de un reconocimiento del derecho a recibir estos servicios. Así, las leyes autonómicas parecen haberse orientado a una cierta universalización limitada, sin que se constituyan derechos que los ciudadanos puedan exigir, ni deberes públicos determinados cuyo cumplimiento pueda ser demandado (Casado, 2002). Sobre este debate, podríamos concluir que la construcción de un sistema estatal de servicios sociales universal, equitativo y con suficiencia financiera, que diese apoyo a las personas en riesgo o con necesidades especiales, se ha quedado a medio camino. A este sistema le falta, de un lado, universalidad en cuanto a derechos $y$, del otro, tal y como veremos a continuación, intensidad protectora en cuanto a contenido, y equidad territorial en recursos y requisitos de accesibilidad.

\subsubsection{Cobertura intensiva}

En la Tabla 2, valoramos la intensidad de la cobertura a través del gasto en servicios sociales por habitante.

Tabla 2. Indicadores de gasto en servicios sociales. España, 2003 (euros)

\begin{tabular}{l|c|c|c}
\hline $\begin{array}{l}\text { Comunidad } \\
\text { autónoma }\end{array}$ & $\begin{array}{c}\text { Población } \\
(\mathbf{1 - 1 - 2 0 0 3 )}\end{array}$ & $\begin{array}{c}\text { Gasto en } \\
\text { servicios } \\
\text { sociales }(\boldsymbol{€})\end{array}$ & $\begin{array}{c}\text { Gasto por } \\
\text { habitante } \\
(\boldsymbol{€})\end{array}$ \\
\hline La Rioja & 293.553 & 41.813 .168 & 142,44 \\
\hline Cantabria & 554.784 & 35.668 .670 & 64,29 \\
\hline Navarra & 584.734 & 100.886 .774 & 172,53 \\
\hline Baleares & 955.045 & 80.550 .000 & 84,34 \\
\hline Asturias & 1.073 .761 & 125.402 .167 & 116,79 \\
\hline Extremadura & 1.075 .286 & 164.718 .945 & 153,19 \\
\hline Aragón & 1.249 .584 & 222.718 .300 & 178,23 \\
\hline Murcia & 1.294 .694 & 74.619 .158 & 57,63 \\
\hline Castilla-La & 1.848 .881 & 358.107 .940 & 193,69 \\
\hline Mancha & 1.915 .540 & 81.759 .180 & 42,68 \\
\hline Canarias & 2.115 .279 & 579.330 .160 & 273,88 \\
\hline País Vasco & 2.493 .918 & 445.798 .683 & 178,75 \\
\hline Castilla y León & 2.750 .985 & 231.488 .921 & 84,15 \\
\hline Galicia & 4.543 .304 & 164.212 .910 & 36,14 \\
\hline Comunidad \\
Valenciana & 5.804 .829 & 678.041 .034 & 116,81 \\
\hline Madrid & 6.813 .319 & 1.013 .323 .554 & 148,73 \\
\hline Cataluña & 7.687 .518 & 738.491 .116 & 96,06 \\
\hline Andalucía & 43.055 .014 & 5.136 .930 .679 & 119,31 \\
\hline Total & & &
\end{tabular}

Fuente: Elaboración propia a partir de Roldán y García Giráldez (2006).

La primera constatación es la gran desigualdad de intensidad entre comunidades autónomas. Según este indicador, podríamos agrupar las comunidades en grupos que irían desde alta intensidad (por encima de los $170 € /$ habitante: País Vasco, CastillaLa Mancha, Castilla y León, Aragón y Navarra), hasta baja intensidad (por debajo de los $60 € /$ habitante: Murcia, Canarias y Comunidad Valenciana). Esta distribución de las comunidades autónomas según el indicador de intensidad coincide con la que se establece según la proporción de empresas y entidades privadas dedicadas al sector de los servicios sociales. País Vasco, Navarra, Aragón y Castilla y León presentan una alta ratio de empresas y entidades de servicios sociales por cada 10.000 habitantes; $y$ la Comunidad Valenciana, Murcia y Canarias, una ratio baja (Couceiro, 2011: 358).

Podríamos profundizar en el estudio de la intensidad de la cobertura analizando los programas autonómicos de rentas mínimas de inserción. El acceso y continuidad en el programa está condicionado al compromiso del beneficiario en la realización de actividades para su inserción. Más allá de una serie de características comunes, hay diferencias muy significativas entre los programas. Si atendemos a los indicadores de cobertura (hogares beneficiarios sobre el número total de hogares), en 2004 (Couceiro, 2011: 359, Tabla 11.5), los valores van desde la alta intensidad de País Vasco o Navarra (3,97\% y 1,43\% de cobertura, respectivamente) hasta las bajas intensidades de Murcia (o,08\%), Castilla-La Mancha (o,1\%), Extremadura $(0,12 \%)$ y la Comunidad Valenciana (o,18\%). Si consideramos los euros por titular que implican estos valores, las disparidades territoriales se hacen todavía más evidentes. La media nacional se situaría en los 3.392 euros por titular, pero los valores irían desde la alta intensidad de Asturias (9.127 $€ /$ titular), Cataluña (4.642€/titular), Extremadura (4.237 $€ /$ titular), Castilla y León (4.173€/titular) y Madrid (4,070€/titular); hasta la baja intensidad de la Comunidad Valenciana (1.443€/titular), Cantabria (1.483€/titular) y La Rioja (1.604 $€ /$ titular). La falta de uniformidad en la regulación interna de estas ayudas ha llevado a una cobertura territorial muy desigual en volumen y colectivos protegidos, y diferentes requisitos de acceso, prestaciones, cantidades y obligaciones.

\subsection{Discusión}

Hemos evidenciado la dificultad de llevar a término un estudio en profundidad sobre el sistema de servicios sociales en España, por lo que, en realidad, debemos referirnos a diecisiete sistemas de servicios sociales.

\subsubsection{Sobre el proceso de descentralización}

A pesar de la fuerte disparidad entre los sistemas autonómicos de servicios sociales, son pocas las diferencias observables si nos centramos en el régimen jurídico que ha regulado esta descentralización. En el análisis de las diecisiete leyes de servicios sociales, encontramos escasas o muy pequeñas variaciones. Parece que estas leyes sufrieron un efecto de mímesis, ya que son muchos los rasgos comunes que comparten. Por tanto, es difícil analizar las diferencias entre los sistemas autonómicos de servicios sociales a través del estudio de su régimen competencial. En primer lugar, debemos referirnos a un trasfondo histórico de escasa consolidación a escala nacional en el momento en el que el sistema 
de servicios sociales se descentralizó. A diferencia de las áreas de educación o sanidad, donde el entramado estatal se había desarrollado y asentado durante la etapa franquista, tanto normativamente como en el plano material y de ejecución, los servicios sociales anteriores a la descentralización partían de una situación marginal de beneficencia o asistencia social muy poco visible tanto política como socialmente. Así, la carencia de una base común a escala estatal, que pudiese haber servido de punto de partida a los diecisiete nuevos sistemas, es la principal raíz de la fragmentación encontrada en el presente. La Constitución permitió una formidable transferencia de poder y recursos a las comunidades autónomas, pero no hizo lo mismo con las corporaciones locales. Por su parte, la Ley Reguladora de Bases de Régimen Local no atribuyó expresamente ninguna responsabilidad en acción social o servicios sociales a las provincias, y trata de manera ambigua las competencias y deberes de los municipios.

\subsubsection{Sobre la financiación}

Esta base histórica e institucional también explicaría la debilidad manifiesta del sistema, lastrado, por una parte, por la financiación insuficiente con que se han dotado los servicios sociales, y por otra, por la falta de reconocimiento de un derecho subjetivo de acceso a los servicios sociales. La Constitución de 1978 falló a la hora de garantizar la universalidad de los nuevos servicios sociales; la falta de concreción ha llevado a la imposibilidad de apelar al derecho a los servicios sociales como un derecho social subjetivo y exigible ante la ley. Esta debilidad jurídica ha propiciado que, en épocas de crisis, esta área social sea la primera en notar los recortes y, por otro lado, que en etapas de bonanza económica el crecimiento no se refleje en un mayor impulso al sistema. Por todo esto, la situación de los servicios sociales continúa siendo marginal si se compara con otras áreas, como la educación o la sanidad, cuyo gasto se sitúa muy por encima. Por tanto, ambas cuestiones, financiación y reconocimiento del derecho subjetivo a los servicios sociales, están íntimamente ligadas, ya que el citado reconocimiento subjetivo marca la escasa visibilidad política y social de esta área social.

\subsubsection{Sobre la cobertura}

Esta doble debilidad tiene una tercera implicación: la de los bajos índices de cobertura del servicio. Si bien, al igual que sucede con la financiación, la extensión de la cobertura se ha ampliado progresivamente en los últimos años, se sitúa muy por debajo de la de otras áreas de la protección social, lo que no hace más que señalar el carácter marginal de este sector dentro del sistema de bienestar español. Todo ello a pesar del universalismo que proclaman la todas las leyes autonómicas de servicios sociales. Precisamente, otra de las características del entramado autonómico de los servicios sociales es la distancia entre la realidad normativa que rige los sistemas y la realidad de su aplicación efectiva. La descentralización ha dado lugar a una gran heterogeneidad entre comunidades autónomas, lo que, obviamente, ha generado una distancia importante entre los diferentes territorios. Aunque la descentralización en sí no debe comportar por fuerza un aumento de las desigualdades entre las diferentes comunidades autónomas, lo cierto es que en el plano de los servicios sociales esto se ha producido en gran medida. De hecho, la desigualdad ha sido doble, ya que el sistema no sólo ha propiciado la aparición de diferencias entre comunidades autónomas, sino que también han aumentado dentro de cada comunidad con la descentralización hacia los municipios.

\subsection{4. ¿Un intento de clasificación?}

En la actualidad, la organización de los servicios sociales ha dado lugar a una serie de problemas, entre los que se pueden destacar los siguientes:

- La desigualdad territorial de acceso que se produce en función del lugar de residencia, a causa de la diferente capacidad de los territorios para implementar los servicios primarios de atención, lo que influye en el nivel de proximidad de estos servicios.

- La ruptura en la continuidad de los cuidados y el apoyo en los casos de traslados de lugar de residencia a otras comunidades autónomas, ya que la colaboración entre diferentes comunidades para abordar situaciones que superen sus respectivos ámbitos territoriales es un aspecto no previsto en las leyes.

- En muchos casos, las diferencias en los modelos organizativos entre las diferentes comunidades autónomas, en la dotación de personal especializado y en la relevancia que se da a cada sector suelen responder más a la sensibilidad política hacia unos determinados colectivos (y a la capacidad de presión política y mediática de éstos) que a un estudio riguroso de las necesidades de la población.

Por las características referidas de fragmentación, debilidad y diferenciación, se hace difícil hablar de tipologías entre los diecisiete sistemas autonómicos de servicios sociales. No obstante, a modo de conclusión de esta dimensión de nuestro análisis, señalamos una posible clasificación:

- El primer grupo lo conforma el eje centro-norte (Asturias, Navarra, País Vasco, Aragón, Cataluña, La Rioja, Extremadura, Castilla-La Mancha, Castilla y León) y se caracteriza por tener los índices más elevados de gasto (tanto por habitante como en el porcentaje del presupuesto autonómico total que representa el presupuesto dedicado a servicios sociales) y cobertura.

- Una segunda agrupación conformada por el eje sur-mediterráneo (Andalucía, Murcia, Canarias, Baleares y la Comunidad Valenciana) y dos 
excepciones del norte (Galicia y Cantabria), que presenta (aunque con excepciones) valores por debajo de la media nacional en las variables referidas de gasto, y por encima en la cobertura.

- Finalmente, un caso intermedio entre estas dos agrupaciones es el de Madrid, cuya posición podría calificarse de ambivalente, porque presenta datos elevados en cuanto al gasto en servicios sociales, pero un valor muy bajo en cuanto a cobertura.

\section{Dimensión operativa ${ }^{4}$}

En este apartado abordamos la dimensión operativa del sistema de servicios sociales, caracterizado como un 'modelo mixto' (público-privado). En primer lugar, se caracterizan los sectores principales de agencia, después se atiende a las características de los recursos humanos del sistema y, finalmente, nos detenemos en las formas de gestión.

\subsection{Red de actores y participación ciudadana}

\subsubsection{Sector público}

En el sistema de servicios sociales intervienen los tres niveles: Administración central, comunidades autónomas y corporaciones locales. El Estado central tiene poco peso; participa en algunos ámbitos que afectan a los servicios sociales, como por ejemplo, en minorías étnicas -como el pueblo gitano-, inmigración, personas mayores y atención a la dependencia, o la responsabilidad sobre algunas prestaciones, como las pensiones no contributivas; la incidencia del Plan Concertado es muy restringida en cuanto a la prestación de equipamientos básicos de servicios comunitarios (Subirats et al., 2007). El grueso de las competencias recae en las comunidades autónomas, que asumen en exclusiva las potestades legislativas y reglamentarias, en virtud del reconocimiento que les da la Constitución de 1978 (art. 148.20), y ejercen en última instancia las responsabilidades públicas y las funciones de control y supervisión. Los Gobiernos autonómicos tienden a convertirse en los últimos responsables respecto a los servicios sociales básicos, aunque sean los municipios los que gestionan los centros de atención primaria. Además, las comunidades autónomas tienden a gestionar en exclusiva los servicios sociales secundarios o especializados. Entre las comunidades autónomas y las corporaciones locales existen organizaciones supramunicipales (mancomunidades, consejos comarcales, diputaciones provinciales) que tratan de dar soluciones a cuestiones organizativas relacionadas con la distribución de competencias y los objetivos de proximidad y descentralización.

\subsubsection{Sector privado}

La participación de la iniciativa privada mercantil de lucro ha cobrado protagonismo en los últimos años. Sin renunciar al principio de responsabilidad pública, se aprecia un notable aumento de la externalización mediante la prestación indirecta de servicios a través de convenios y conciertos. Pero según Fantova (2007), faltan canales de comunicación entre iniciativa privada y administración pública que permitan una sinergia de ambos actores. Desde los sectores privados, se ha incidido en la carencia de una fórmula jurídica específica para los conciertos públicos con las entidades privadas; una de las propuestas de mejora efectuada desde los ámbitos profesionales es la creación de leyes orgánicas específicas para el ámbito de los servicios sociales, como ya existen en educación o sanidad (Alonso Seco, 2007). Esta medida simplificaría y agilizaría la burocracia administrativa, mejorando la coordinación en las relaciones existentes entre el sector privado y la Administración.

\subsubsection{Tercer sector}

El tercer sector se define como alternativa organizativa de la sociedad civil frente al sector público y el sector privado, y presenta unos rasgos característicos que permiten delimitarlo: la exención de impuestos, la voluntariedad, la donación y la ausencia de lucro. Este sector toma un papel protagonista en la reconstrucción de la sociedad civil, fomentando un reconocimiento solidario de la ciudadanía, que asume responsabilidades tradicionalmente asignadas al sector público.

\subsubsection{Sector informal}

Como afirma Gregorio Rodríguez Cabrero (2007), la familia es el principal soporte de atención a los necesitados y, dentro de ella, destaca el rol de la mujer como cuidadora informal. En los países del sur de Europa, las familias y, más concretamente, las mujeres, son la columna vertebral del sistema de cuidados personales. Los sectores informales, especialmente las redes familiares, adquieren una relevancia en la protección frente a la exclusión difícilmente mensurable. Aun así, la tendencia del sistema público de servicios sociales es la penalización "por la existencia de redes naturales de relación social" (Sarabia, 2007). En la mayoría de baremos para la provisión de servicios, la presencia de redes de solidaridad familiar es un factor de penalización, si no de exclusión directa, ya que para muchos beneficios se tienen en cuenta los ingresos de todos los miembros. La progresiva externalización de servicios, con la generalización de modelos de provisión basados en el copago de los usuarios (o de sus familias), agudiza el problema.

\subsubsection{Participación ciudadana individual}

lítiques auto, .; e Iglesias, M. (2011): “La dimensió operativa en les po J. (dirs.), Autonomies i desigualtats a Espanya: percepcions, evolució social $i$ polítiques de benestar, Barcelona, Institut d'Estudis Autonòmics, págs. 365-384.
Dentro del discurso oficial que viene orientando las políticas públicas del sistema de servicios sociales, 
uno de los elementos de énfasis es la participación del usuario en la acción contra la exclusión social. La idea de gobernanza y política social de inclusión activa, como un proceso de implicación de los propios usuarios, aparece como uno de los puntos destacados del V Plan Nacional de Acción para la Inclusión Social (PNAIn), como un principio guía que debería orientar los diversos planes de acción de las comunidades autónomas y las corporaciones locales. Las medidas orientadas en este sentido incluyen prácticas de elaboración común de los programas de inclusión, donde el trabajador social y el beneficiario elaboran conjuntamente los programas de acción, subrayando el papel del ciudadano como sujeto activo del proceso de transformación. La participación de los ciudadanos a escala individual en tanto que beneficiarios de los servicios sociales se realiza a través de talleres, seminarios y reuniones individualizadas, donde las ideas de aquéllos se concretan en documentos y sugerencias que se incluyen en los programas y planes de acción individual. Posturas críticas señalan que este tipo de colaboración personalizada reedita la acción focalizada sobre ciertos usuarios, subrayando su papel de excluidos, con efectos perversos de estigmatización. La situación de comunicación asimétrica establecida entre el trabajador social, representante de la institución, y el usuario individual que participa del programa, reproduciría el desnivel entre poseedor de recursos y necesitado. Este riesgo se evidenciaría al comprobar que las funciones de evaluación y supervisión de los programas quedarían siempre en manos de los trabajadores institucionales. Frente a esta forma de participación individual, se plantea la alternativa de la participación comunitaria como mecanismo efectivo a la hora de ejercer la responsabilidad cívica.

\subsubsection{Participación ciudadana colectiva}

En los consejos generales autonómicos participan representantes de la Administración (autonómica y local) y de las entidades sociales (asociaciones de afectados, entidades de iniciativa social que actúan en el ámbito, sindicatos y asociaciones empresariales, representantes de los profesionales). Las funciones de estos consejos son consultivas, y se centran en la redacción de informes y memorias, el seguimiento y coordinación de actuaciones, y la presentación y estudio de propuestas. A escala local, estos entes consultivos tienden a reproducir la proporción de representantes, intentando reflejar la diversidad del sistema (Guillén y Vilà, 2007). Queremos destacar la participación de los colegios profesionales de trabajadores sociales de las diferentes provincias y comunidades, organizados a escala estatal en el Consejo General de Colegios de Trabajo Social, que no se limita a la mera acción técnica, sino que en más de una ocasión funciona como elemento crítico, reivindicando más presencia de los debates sobre los servicios sociales en los foros políticos.

En suma, el sistema de servicios sociales se presenta como un complejo entramado de actores, donde los servicios garantizados por la responsabilidad pública son provistos por actores de diferentes tipos. En esta distribución de tareas se observa una especialización funcional. Como vimos, los servicios sociales comunitarios o de base son competencia prioritaria de las corporaciones locales y tratan de generar sinergias provechosas con la iniciativa social. Pero estas sinergias, si no se organizan de forma coordinada, pueden generar problemas de duplicidad y superposición, y producir confusión entre los usuarios al multiplicar las puertas de entrada al sistema (Sarabia, 2007). Respecto a los servicios sociales especializados, la iniciativa mercantil tiene mayor presencia en sectores susceptibles de obtener beneficios, como la atención a la drogodependencia, mayores o enfermos crónicos (centros de día, residencias). Por el contrario, sectores como la atención de personas sin hogar son cubiertos casi en exclusiva por administraciones públicas y entidades no lucrativas.

\subsection{Servicios sociales y recursos humanos}

Al tratar de hacer una aproximación analítica al tema, nos encontramos que, por un lado, las fuentes son variadas y raramente permiten un análisis cronológico o comparativo de los datos; por otro, al tratarse de un sistema tan diverso y fragmentado, los sistemas de información a escala estatal no han logrado, como en las áreas de salud o educación, una mayor sistematización de la información. Pese a ello, esbozaremos las principales características del sector respecto al empleo, a partir de los datos elaborados por el Observatorio de Relacionas Industriales del Consejo Económico y Social en 2006:

- Importante y veloz crecimiento de la ocupación en el sector: según datos de la Encuesta de Población Activa, el empleo asalariado total se estimaba en 338.440 personas en $\mathbf{2 0 0 6}$, lo que significa el $1,7 \%$ del total de asalariados. Asimismo, la evolución del empleo en el sector se duplica desde 1999 a 2004; aumenta en un 70,6\% entre 2004 y 2006; y se estima que esta tendencia creciente se mantendrá.

- Estructura organizativa basada en pequeñas y medianas empresas y entidades: la media de trabajadores para las empresas y entidades prestadoras de servicios es de 24 y 20 personas, respectivamente.

- Elevada feminización del sector: las trabajadoras constituyen el $84 \%$ del total de las 338.000 personas que trabajan en este sector.

- Alto nivel de formación de la mano de obra, con un $29,5 \%$ de titulados universitarios y un $17 \%$ con título de formación profesional, cifras que superan la media española de todos los sectores (21\% y $8 \%$, respectivamente).

- Fuerte presencia de trabajadoras latinoamericanas. El total de trabajadores extranjeros empleados en esta rama de actividad es del $12 \%$. Las latinoamericanas suponen el $62 \%$ del 
total, seguidas por las africanas (16\%), por lo que cabe decir que constituye un importante nicho de empleo para estos colectivos.

- Contratación temporal y predominancia del sector privado, con una media de contratos temporales ocho puntos por encima de la del conjunto de la población empleada, lo que da una muestra de la precariedad de este sector laboral, paralela a su expansión. Por otro lado, tres cuartas partes de los asalariados pertenecen al sector privado, ya sean empresas mercantiles o entidades sin ánimo de lucro.

- Alta exigencia e intensidad en las condiciones de trabajo. Según la opinión de los trabajadores, esta rama de actividad es la que registra más exigencias mentales respecto al nivel de atención requerido, el ritmo, la cantidad de trabajo y las consecuencias de los errores (V Encuesta Nacional de Condiciones de Trabajo, 2003). Además, tanto en estudios de tipo cuantitativo como en los de tipo cualitativo, la percepción de los trabajadores sobre el estatus y el reconocimiento del sector dentro de los servicios públicos es muy bajo (Subirats et al., 2007).

- Heterogeneidad de las condiciones entre sectores e intrasectores: la heterogeneidad y desigualdad de condiciones de contratación es notable entre el sistema público y los proveedores privados. Incluso dentro del sector público, la fragmentación institucional facilita la reproducción de las desigualdades entre los diversos niveles de atención en un mismo territorio. Así, los servicios especializados que suelen depender de las comunidades autónomas presentan, en general, ventajas comparativas con respecto a las contrataciones de los municipios, de los cuales depende la atención primaria. Asimismo, las diferencias se reproducen entre las diferentes comunidades autónomas, al no regirse por un marco general de contratación, condiciones y regulación.

\subsection{Formas de gestión}

\subsubsection{Planificación multinivel y coordinación}

El hecho de que las competencias en servicios sociales estén concentradas principalmente en el ámbito autonómico, pero la gestión y la actuación directa se encuentren distribuida en múltiples organizaciones (públicas, privadas, iniciativa social) y administraciones (autonómicas, municipales y supramunicipales) ha producido una gran fragmentación, donde es frecuente la duplicidad y la superposición de acciones.

Los principales instrumentos de coordinación multinivel son los planes nacionales de acción para la inclusión social (PNAIn), que siguen la tendencia europea establecida en la Estrategia de Lisboa (2000). Así, de acuerdo con el planteamiento de la Comisión Europea, los PNAIn buscan una convergencia de las medidas adoptadas por los diferentes Estados miembros en asuntos en los que ostentan competencias exclusivas. Siguiendo una lógica de coordinación horizontal, los documentos adoptan formas de 'derecho indicativo', sin ostentar la categoría de reglamentos o directivas. A pesar de estos esfuerzos hacia la convergencia, la fragmentación de programas crea, en la práctica, diecisiete subsistemas independientes y escasamente coordinados (Sarabia, 2007). En el plano operativo, ello se refleja en los diferentes planes autonómicos de inclusión (PAIn), que se desarrollan en infinidad de planes sectoriales e instituciones descentralizadas de las consejerías destinadas a colectivos concretos de la población.

A pesar de la diversidad y fragmentación, existen elementos en común entre las diferentes comunidades autónomas, como la consideración de la proximidad de los servicios sociales como un valor indispensable, con la capacidad de personalizar y adecuar las medidas necesarias a cada usuario. Asimismo existen una serie de medidas que aparecen como potencialmente mejores para optimizar la gestión; destacan propuestas como la 'puerta única' (para la entrada al sistema), el profesional de referencia (que permite estrategias de case management), o el sistema de información del usuario de servicios sociales (ficha informática del usuario con finalidades técnicas).

\subsubsection{División organizativa en el diseño institucional}

Los servicios sociales básicos se diseñan como un servicio polivalente destinado a cubrir las prestaciones básicas encargadas a las corporaciones locales. Los equipamientos básicos propios de este nivel son el centro de servicios sociales, el centro de acogida y los albergues. A través de estos equipamientos, se proporcionan prestaciones mínimas, que incluyen:

- Información y orientación. Esta prestación se caracteriza por su ambigüedad, y por lo tanto, no es extraño encontrar una amplia diversidad a la hora de dar por cubierta esta prestación. La concepción mayoritaria de esta prestación es la de 'puerta de entrada'.

- Ayuda a domicilio (ayudas de tipo sociorrelacional, material o de carácter complementario).

- Alojamiento y convivencia en casos que requieren de un 'ambiente familiar adecuado' (albergues, centros de acogida, centros de día y viviendas tuteladas).

- Prevención e inserción social, donde el equipo específico más común suele ser el centro ocupacional.

- Cooperación social y fomento del voluntariado.

Por su parte, en los servicios sociales especializados predomina una estructuración por colectivos. Esta estructura legislativa, combinada con la intención totalizadora y omnicomprensiva de las administraciones autonómicas lleva a la sobrecarga del sistema, que se fragmenta en infinidad de institutos y órganos específicos de gestión. 
Para terminar con este apartado, señalamos la necesidad de una correcta delimitación competencial y de responsabilidades en las leyes, que evite las duplicidades entre administraciones, así como el desdibujamiento de las responsabilidades respecto a los derechos y deberes de los usuarios y los proveedores privados de servicios sociales (Alonso Seco, 2007; Guillén y Vilà, 2007).

\subsubsection{Transversalidad con otros sistemas}

El sistema de servicios sociales está destinado a actuar conjuntamente con "otras ramas del árbol social” (Casado, 2007a). Algunos de los sectores donde esta transversalidad o acción coordinada está más presente son la asistencia sanitaria, los servicios educativos, las políticas de rentas personales o la protección social a la vivienda. En los actuales sistemas de servicios sociales, no tenemos constancia de colaboraciones formales a escala macro (entre sistemas, ramas, redes) o meso (entre organizaciones o instituciones), aunque podemos intuir que existen formas de acción informal a escala micro (entre unidades de actuación) mediante la empatía entre profesionales (Subirats et al., 2007). La actuación conjunta con la rama de la asistencia sanitaria puede ser quizás el ejemplo de esta transversalidad más evidente. Pero podemos concluir que la colaboración transversal dista mucho de ser una actividad normalizada entre los diferentes departamentos de las consejerías autonómicas o concejalías municipales de servicios sociales.

\subsubsection{Modelos de provisión del bienestar}

El sistema de servicios sociales ya ha sido definido como un sistema mixto, donde la presencia del sector público es mucho menos significativa que en otros sistemas de bienestar, con un importante factor de externalización apoyado en la presencia de la iniciativa mercantil y social. La formalización de un catálogo de servicios que no sólo sea público, o que se difunda como una de las tareas de información y orientación propias del sistema público de servicios sociales, sería un primer paso necesario para posibilitar una gestión racional, coordinada y flexible del sistema público de servicios sociales (Casado, 2007a). La intención de formalizar un catálogo de servicios sociales (cartera de prestaciones) aparece reflejada en las últimas leyes autonómicas y en los últimos años ha comenzado a aparecer mediante decretos de los diferentes Gobiernos autonómicos (Navarra, Decreto Foral 69/2008; Cataluña, Decreto 151/2008). En éstas se especifica que los servicios sociales serán derechos exigibles, y se incluyen otros que estarán disponibles "según la dotación presupuestaria”.

\subsection{5. ¿Una propuesta de clasificación?}

Teniendo en cuenta el análisis de la dimensión operativa de los servicios sociales, podríamos hablar a priori de diecisiete sistemas independientes de servicios sociales con características diversas, a partir de los siguientes ejes:

- Externalización: como sistema mixto de responsabilidad pública, la Administración, en cualquiera de sus niveles, aunque fundamentalmente en el autonómico, aparece como última responsable del funcionamiento del sistema. No obstante, como hemos observado a lo largo del estudio, la prestación de servicios por parte de la iniciativa privada y las entidades sin ánimo de lucro aparece como una forma extendida de proveer servicios de bienestar. La Administración, por su parte, ejerce su responsabilidad mediante el ejercicio de la función normativa, la planificación general, y la supervisión y vigilancia del resto de agentes.

- Descentralización: los servicios sociales aparecen, en principio, como competencia exclusiva de las comunidades autónomas, pero la presión de los problemas recae sobre las administraciones locales, que no disponen de una normativa que delimite claramente sus competencias, ni los recursos necesarios para hacerles frente.

- Participación ciudadana: la participación de los diferentes agentes que conforman el sistema de servicios sociales se presenta como una medida de optimización de la gestión, extiende el debate más allá de los aspectos estrictamente técnicos y permite el cuestionamiento de los recursos destinados a este sistema y su evaluación.

- Coordinación: los sistemas de servicios sociales integran una gran diversidad de agentes con objetivos y demandas diversos, pero los intentos de crear un sistema de coordinación aparecen de manera difusa en las diferentes comunidades autónomas, como un constante desiderátum, sin que se puedan apreciar diferencias claras entre ellas.

Teniendo en cuenta estos ejes y las diferentes variables mencionadas en este apartado encontramos, en líneas generales, unos sistemas de servicios sociales gestionados de manera descoordinada y sin unos fundamentos claros, que orienten las actuaciones como un bloque. Encontramos estrategias de mimetismo en la aplicación de técnicas y medidas concretas, y se observa una tendencia hacia la homogeneización en los principios rectores, desarrollos normativos y formas de gestión, aun cuando a ritmos muy irregulares. Frente a esta situación, todo intento de clasificación ha resultado estéril.

\section{Conclusiones}

La red existente de servicios sociales se caracteriza por su fragmentación y debilidad. Se ha construido a partir de un legado de marginalidad (y a veces, de inexistencia) heredada de la beneficencia del régimen predemocrático. La política de servicios sociales presenta un mapa muy heterogéneo en su despliegue territorial. Esto no sólo es debido a que se trata de un ámbito de competencia exclusiva de las comunidades autónomas 
en el que se han mostrado muy activas; también deriva de la práctica ausencia de actuaciones que, bien desde el Gobierno central5, bien desde las mismas autonomías, se hayan orientado a fundamentar ningún zócalo o base común de compromiso en la definición de estos servicios. Si sumamos la financiación insuficiente del sistema que ha acompañado la descentralización, no sólo hacia las autonomías, sino, dentro de éstas, hacia los municipios, el escenario es de una red extremadamente heterogénea y débil, tanto en la extensión como en la intensidad de la cobertura que se ofrece. De este modo, no sólo existen disparidades territoriales entre autonomías, sino también entre municipios dentro de la misma comunidad autónoma.

Como hemos observado en el análisis, las disparidades afectan tanto a las opciones sustantivas como a las operativas. En cuanto a la dimensión sustantiva, se ha tratado el proceso de descentralización según la Constitución, los estatutos de autonomía y las leyes de servicios sociales, destacando el alto grado de homogeneidad normativa en el desarrollo de las competencias transferidas. A continuación, se ha analizado la financiación de esta política a escala autonómica, en la que la debilidad de recursos es el rasgo común. Sin duda, indicadores como la evolución del gasto per cápita y el peso de este esfuerzo dentro del presupuesto de la comunidad autónoma dicen mucho sobre el grado de compromiso de los Gobiernos autonómicos con determinados servicios o problemáticas. Finalmente, nos hemos aproximado a la cobertura tanto extensiva como intensiva. Es en la cobertura donde se encuentran los rasgos diferenciales, que parecen responder más a contextos políticos coyunturales que a necesidades 0 realidades específicas de cada comunidad autónoma. Precisamente, una de las características del entramado autonómico de los servicios sociales es la distancia entre la realidad normativa que rige los sistemas y la realidad de su aplicación efectiva.

Esta heterogeneidad también se observa en la dimensión operativa. Entre las comunidades autónomas existen diferencias en cuanto a carteras de servicios y colectivos beneficiarios, y también se dan en la composición de la red de prestación de los servicios. No obstante, se observa una tendencia común al incremento, en muchos casos exponencial, del número de entidades y empresas de servicios sociales en todas las comunidades autónomas. Igualmente, es común a todas las autonomías la tendencia a fundamentar el crecimiento del sector en la expansión de la prestación por parte de proveedores privados, con y sin ánimo de lucro, a potenciar las transferencias monetarias y al incremento de la financiación mediante copagos por parte de los beneficiarios.

A pesar de esta heterogeneidad territorial en extensión e intensidad de la cobertura, y en la composición de las redes de prestación de los servicios, la dimen-

${ }^{5}$ Ausencia rota, y de forma polémica (por lo que tenía de intromisión en un espacio considerado plenamente de competencia autonómica), con la aprobación de la Ley de Promoción de la Autonomía personal y atención a las personas en situación de dependencia. Ni la ley ni su despliegue han sido objeto de análisis en este trabajo. sión simbólica, esto es, el discurso y la definición normativa de los principios que rigen esta política, presenta una clara homogeneidad en toda la normativa autonómica. En este sentido, se pueden inferir procesos de difusión y convergencia en los marcos cognitivos que fundamentan las intervenciones públicas en este ámbito. A veces, los itinerarios de la difusión circulan entre comunidades autónomas y, de ellas, hacia instancias de Gobierno superiores; a veces, desde el Gobierno central o incluso instancias internacionales hacia los Gobiernos subestatales.

La evolución de este discurso presenta una trayectoria común, que indicaría un cambio de paradigma. En una primera fase, desde principios de los ochenta hasta principios los noventa, aparecían como principios rectores el universalismo y la responsabilidad pública en la provisión y la prestación de los servicios. Pero esta proclamación coexistía con la indefinición de un derecho subjetivo a la asistencia social, que también encontrábamos a la Constitución. La responsabilidad pública se traducía en el predominio de la prestación pública directa por parte de las estructuras institucionales autonómicas, con la hegemonía de un marco cognitivo generado por los colectivos profesionales del sector. Estos principios se mantuvieron también en la primera oleada de leyes autonómicas de rentas mínimas de inserción. Aun así, el discurso empezó a incorporar el concepto del derecho a la inserción que provenía de nuevas voces en la política de servicios sociales, principalmente la Unión Europea.

Una segunda fase en la evolución de la política se inicia a mediados de la década de 1990 y llegaría hasta principios de la de 2000 . En este periodo las comunidades autónomas reforman sus leyes de servicios sociales. Del universalismo y la responsabilidad pública se transita hacia el selectivismo, la prestación indirecta y el altruismo. Así, se da entrada a la iniciativa privada con ánimo de lucro y al tercer sector como prestadores de servicios. Siguiendo directrices europeas, los programas autonómicos de rentas mínimas de inserción se vinculan a las políticas de empleo, y aparecen los planes nacionales de inclusión social. De nuevo, estas directrices dejan un alto grado de discrecionalidad tanto a los Estados miembros cómo a las instituciones subestatales, que, en el caso español, se ha traducido en bajos niveles de compromiso con el despliegue de la política.

Desde principios de la década de 2000 hasta la actualidad, las nuevas leyes autonómicas de servicios sociales abogan, por un lado, por una más clara subjetivación de derechos y, de otro, por la cofinanciación por parte de los beneficiarios de los servicios, mientras consolidan el modelo de prestación indirecta basada en la iniciativa privada con o sin ánimo de lucro. A su vez, las nuevas leyes autonómicas de rentas mínimas de inserción profundizan el vínculo con las políticas de empleo. En general, pues, la tendencia es a la profundización del reconocimiento de los derechos, pero cofinanciados en función de la renta y patrimonio del beneficiario, y con prioridad de las transferencias monetarias sobre la prestación de servicios. 


\section{Referencias bibliográficas}

ADELANTADO, J. (2011): “La dimensió simbòlica en les polítiques autonòmiques de serveis socials i assistència social", en GALLEGO, R.; y SUBIRATS, J. (dirs.), Autonomies i desigualtats a Espanya: percepcions, evolució social $i$ polítiques de benestar, Barcelona, Institut d’Estudis Autonòmics, págs. 319-340.

ALEMÁN, C.; y GARCÍA SERRANO, M. (2005): Servicios sociales sectoriales, Madrid, Editorial Universitaria Ramón Areces.

ALONSO SECO, J. M. (2007): "Mejoras jurídico institucionales en los servicios sociales", en CASADO, D.; y FANTOVA, F. (coords.), Perfeccionamiento de los servicios sociales en España. Informe con ocasión de la ley sobre autonomía y dependencia, Madrid, Caritas Española Editores; Fundación FOESSA, págs. 373-413.

ALONSO SECO, J. M.; y GONZALO GONZÁLEZ, B. (1997): La asistencia social y los servicios sociales en España, Madrid, Boletín Oficial del Estado.

ARRIBA, A. (2002): "Procesos de implantación de políticas de rentas mínimas de inserción en España", en MORENO, L. (ed.), Pobreza y exclusión: la 'malla de seguridad' en España, Madrid, CSIC, págs. 175-220.

AUST, A.; y ARRIBA, A. (2006): "Towards activation? Social assistance reforms and discourses", en TAYLOR-GOOBY, P. (ed.), Ideas and Welfare State Reform in Western Europe, Nueva York, Palgrave-Macmillan, págs. 100-123.

BAREA, J. (dir.) (1996): El gasto público en servicios sociales en España, Madrid, Ministerio de Trabajo y Asuntos Sociales.

BÖRZEL, T. A. (2002): “Pace-setting, foot-dragging and fence-sitting: Member state responses to Europeanization", Journal of Common Market Studies, vol. 40, nํㅡ, págs. 193-214.
CASADO, D. (2007a): "Demandas y reforma de la oferta técnica de los servicios sociales", en CASADO, D.; y FANTOVA, F. (coords.), Perfeccionamiento de los servicios sociales en España. Informe con ocasión de la ley sobre autonomía y dependencia, Madrid, Caritas Española Editores; Fundación FOESSA, págs. 35-47.

- (2007b): “La rama de los servicios sociales”, en CASADO, D.; y FANTOVA, F. (coords.), Perfeccionamiento de los servicios sociales en España. Informe con ocasión de la ley sobre autonomía y dependencia, Madrid, Cáritas Española Editores; Fundación FOESSA, págs. 101-145.

- (2002): Reforma política de los servicios sociales, Madrid, Editorial CCS.

CASTEL, R. (2002): "Du travail social à la gestion du nontravail”, en LELEUX, C. (ed.), L'assistant social entre aide et contrôle social, Bruselas, IESSID, págs. 167-192.

COUCEIRO, M. (2011): "La dimensió substantiva en les polítiques autonòmiques de serveis socials", en GALLEGO, R.; y SUBIRATS, J. (dirs.), Autonomies i desigualtats a Espanya: percepcions, evolució social i polítiques de benestar, Barcelona, Institut d'Estudis Autonòmics, págs. 341-364.

EBBINGHAUS, B. (2005): Can Path Dependence Explain Institutional Change? Two Approaches Applied to Welfare State Reform, serie: MPIfG Discussion Paper, no 05/2, Colonia, MaxPlanck-Institut für Gesellschaftsforschung [<http://edoc.mpg.de/270944'].

FANTOVA, F. (2007): “Elementos de diagnóstico técnico e institucional de los servicios sociales en España y propuestas para su mejora", en CASADO, D.; y FANTOVA, F. (coords.), 
Perfeccionamiento de los servicios sociales en España. Informe con ocasión de la ley sobre autonomía y dependencia, Madrid, Caritas Española Editores; Fundación FOESSA, págs. 209-256.

GAITÁN MUÑOZ, L. (1991): "Servicios sociales: reflexiones para después de una década", Cuadernos de Trabajo Social, no 4-5, págs. 11- 25.

GALLEGO, R.; y SUBIRATS, J. (2011): Autonomies $i$ desigualtats a Espanya: percepcions, evolució social i polítiques de benestar, Barcelona, Institut d'Estudis Autonòmics.

GUILLÉN, E.; y VILÀ, A. (2007): "Los cambios legislativos recientes en materia de servicios sociales", en CASADO, D.; y FANTOVA, F. (coords.), Perfeccionamiento de los servicios sociales en España. Informe con ocasión de la ley sobre autonomía y dependencia, Madrid, Caritas Española Editores; Fundación FOESSA, págs. 147-175.

HALL, P. (1993): "Policy paradigms, social learning, and the State: The case of economic policymaking in Britain”, Comparative Politics, vol. 25, $\mathrm{n}^{0} 3$, págs. 275-296.

HOOGHE, L.; y MARKS, G. (2001): Multilevel Governance and European Integration, Langham, Rowman and Littlefied.

LAPARRA, M. (2004): "La travesía del desierto de las rentas mínimas en España”, Documentación Social, nํ. 135, págs. 57-76.

LOUGHLIN, J. (2007): "Reconfiguring the State: Trends in territorial governance in European States", Regional and Federal Studies, vol. 17, no 4, págs. 385-403.

MAHONEY, J. (2000): "Path dependence in Historical Sociology", Theory and Society, vol. 29, $\mathrm{n} \div 4$, págs. 507-548.

RADAELLI, C. M. (2003): "The Europeanization of public policy”, en FEATHERSTONE, K.; y RADAELLI, C. M. (eds.), The Politics of Europeanization, Oxford, Oxford University Press, págs. 27-56.

RENES, V.; LORENZO, F.; y CHAHIN, A. (2007): Poniendo en práctica la Estrategia Europea para la Inclusión
Social. Del plano europeo al plano local, serie: Cuadernos Europeos, nํㅜ 4, Fundación Luis Vives [/http://www.fundacionluisvives.org/ upload/16/16/cuaderno_europeo4.pdf〉].

RODRÍGUEZ CABRERO, G. (2007): “Financiación de los servicios sociales con especial referencia a la Ley de Promoción de la Autonomía Personal y Atención a las personas en situación de dependencia: situación y propuestas de mejora", en CASADO, D.; y FANTOVA, F. (2007), Perfeccionamiento de los servicios sociales en España. Informe con ocasión de la ley sobre autonomía y dependencia, Madrid, Caritas Española Editores; Fundación FOESSA, págs. 355-371.

- (1990): El gasto público en servicios sociales en España (1972-88), Madrid, Ministerio de Asuntos Sociales.

ROLDÁN GARCÍA, E.; y GARCíA GIRÁLDEZ, T. (2006): Políticas de servicios sociales, Madrid, Síntesis.

SARABIA, A. (2007): "Propuestas de mejora en la organización y gestión de los servicios sociales. Diagnóstico funcional y sugerencias de cambio", en CASADO, D.; y FANTOVA, F. (coords.), Perfeccionamiento de los servicios sociales en España. Informe con ocasión de la ley sobre autonomía y dependencia, Madrid, Caritas Española Editores; Fundación FOESSA, págs. 325-353.

SCHMIDT, V. A. (2008): "Discursive institutionalism: The explanatory power of ideas and discourse", Annual Review of Political Science, $\mathrm{n}$ - 11 , págs. 303-26.

SOUTO, J.; e IGLESIAS, M. (2011): "La dimensió operativa en les polítiques autonòmiques de serveis socials", en GALLEGO, R.; y SUBIRATS, J. (dirs.), Autonomies i desigualtats a Espanya: percepcions, evolució social i polítiques de benestar, Barcelona, Institut d'Estudis Autonòmics, págs. 365-384.

SUBIRATS, J. et al. (2007): Los servicios sociales de atención primaria ante el cambio social, Madrid, Ministerio de Trabajo y Asuntos Sociales. 